\title{
Contribuições da Engenharia Didática como elemento norteador no Ensino de Física: estudando o fenômeno de Encontro de Corpos com atividades da Robótica Educacional
}

Contributions of Didactic Engineering as a guiding element in the Teaching of Physics: studying the phenomenon of Meeting of Bodies with activities of Educational Robotics

\author{
José Roberto Lima*1@ Helaine Ferreira ${ }^{2 @}$ \\ ${ }^{1}$ Instituto Federal de Pernambuco, Recife, PE, Brasil \\ ${ }^{2}$ Universidade Federal Rural de Pernambuco, Recife, PE, Brasil
}

Recebido em 27 de Janeiro de 2019. Revisado em 14 de Junho de 2019. Aceito em 31 de Julho de 2019

\begin{abstract}
Esta pesquisa teve como objetivo desenvolver uma sequência de ensino e aprendizagem do fenômeno do Encontro de Corpos em Movimento Uniforme, articulando elementos da Engenharia Didática e a dinâmica da experimentação, com a Robótica Educacional. O delineamento metodológico foi orientado pelas etapas da Engenharia Didática: Análise Preliminar, Concepção e Análise a priori das Situações Didáticas, Experimentação e a Análise a posteriori, e Validação, que nortearam a construção do processo de ensino e aprendizagem, sua implementação em contextos de uma escola de Ensino Médio e sua análise. Os resultados de nossas observações indicaram melhorias nas estratégias de resolução das questões envolvendo o fenômeno do Encontro de Corpos, a partir da estruturação das equações horárias de espaço de cada robô e igualar as suas posições para determinar o instante de encontro. Os elementos da Engenharia Didática presentes em nossas investigações nos permitiram acompanhar e planejar necessidades de retrabalho docente para superação dos obstáculos e perceber lacunas de compreensões conceituais. Já o uso da Robótica, como ferramenta educacional, propiciou um ambiente de construção e experimentação diferenciado para a abordagem do fenômeno de Encontro de Corpos.
\end{abstract}

Palavras-chave: Engenharia Didática, Ensino de Física, Robótica.

\begin{abstract}
This research had as objective to develop a sequence of teaching and learning of the phenomenon of the Meeting of Bodies in Uniform Movement, articulating elements of Didactic Engineering and the dynamics of experimentation, with Educational Robotics. The methodological design was guided by the stages of Didactic Engineering: Preliminary Analysis, Conception and a priori Analysis of Teaching Situations, Experimentation and a posteriori Analysis, and Validation, which guided the construction of the teaching and learning process, its implementation in contexts of a high school and its analysis. The results of our observations indicated improvements in the strategies of solving the questions involving the phenomenon of the Meeting of Bodies, from the structuring of the hourly equations of space of each robot and matching their positions to determine the instant of encounter. The elements of Didactic Engineering present in our investigations have allowed us to follow and plan teacher reworking needs to overcome obstacles and perceive gaps in conceptual comprehension. The use of robotics, as an educational tool, provided an environment of differentiated construction and experimentation for the approach of the phenomenon of Bodies Meeting.

Keywords: Didactic Engineering, Teaching Physics, Robotics.
\end{abstract}

\section{Introdução}

Na educação científica, uma frutífera área de pesquisa e desenvolvimento envolve a concepção, implementação e validação de sequências curtas e temáticas para o ensino de ciências em diversas áreas.

Uma sequência de ensino é tanto um processo de pesquisa intervencionista como um produto, compreendendo

*Endereço de correspondência: jroberto@pesqueira.ifpe.edu.br atividades de ensino-aprendizagem empiricamente adaptadas ao raciocínio do aluno [1].

Segundo Meheut e Psillos [1], uma sequência de ensino desenvolve-se gradualmente a partir de várias implementações, a partir de um processo evolutivo cíclico iluminado por dados de pesquisa, o que resulta em seu enriquecimento.

Escolhemos a Engenharia Didática Clássica para nortear a pesquisa em questão, apesar da sua utilização no 
ensino de física ainda ser recente, se comparamos sua aplicabilidade no campo da matemática.

Optamos por articular, à utilização da Engenharia Didática, a Robótica Educacional. Seu uso como ferramenta pedagógica impulsiona o desenvolvimento de habilidades interessantes no ensino da Física, assim como também aprimora competências comuns a todas as áreas de conhecimento. A proposta da Robótica Educacional é de mobilizar os estudantes, em trabalho colaborativo, a montarem um aparato automatizado, o robô, tentando resolver os desafios propostos. A implementação da dinâmica de Robótica requer um kit, composto por elementos eletroeletrônicos e mecânicos, para controle e programação dos dispositivos, provocando movimento e gerenciamento de ações diante das respostas às variações de estado dos sensores utilizados. No mercado educacional, temos kits que impõem que os dispositivos de movimento, os motores, e os sensores a serem utilizados nas montagens dos projetos sejam adquiridos junto ao fabricante, enquanto que outros kits adotam a filosofia de plataformas livres, conhecidos como os Arduínos os quais admitem a liberdade de acesso ao reaproveitamento de materiais reciclados de equipamentos eletroeletrônicos sucateados $[2,3,4]$.

Diante do exposto, destacamos que a nossa contribuição de investigação reside em estudar situações reais do ensino de física, mais especificamente, o Encontro de Corpos de Movimento Uniforme, criadas a partir de atividades de montagem e programação de robótica, a partir do arcabouço teórico- metodológico da Engenharia Didática, o que nos possibilita, dentre muitas coisas, acompanhar de forma gradual as várias etapas de implementação das atividades de ensino.

\section{Engenharia Didática como ferramenta teórica e metodológica}

Com a intenção de disponibilizar recursos e meios de melhorar a dinâmica do trabalho em sala de aula, participantes da escola da Didática da Matemática Francesa, Yves Chevallard e Guy Brousseau, em 1982, contribuíram com noções e bases da Engenharia Didática Clássica. Em 1989, Michèle Artigue associou a Engenharia Didática a uma metodologia de análise de situações didáticas e comparou a dinâmica do trabalho do pesquisador similar ao ofício de um engenheiro. Sabendo que o trabalho do engenheiro requer o desenvolvimento de um projeto de execução, com controle científico, se apoiando em fundamentos teóricos da área ponderando sobre a complexidade de todos os elementos envolvidos e recursos disponíveis, além de acompanhar a execução do projeto avaliando todas as etapas da execução prática. O ofício do professor em seu processo de ensino se assemelha, pois, requer os mesmos cuidados e compromissos em seu planejamento e em sua execução, sempre avaliando todas as etapas de sua implementação prática $[5,6]$.
A proposta da Engenharia Didática consistiu na estruturação de um quadro teórico capaz de criar situações didáticas de aprendizagens e de nortear um referencial metodológico para análise das práticas e dos fenômenos de ensino investigados. A Engenharia Didática tem se estabelecido em duas formas de aplicações: uma como ferramenta metodológica de pesquisa qualitativa na área da Matemática e outra com a dinâmica norteadora para elaboração e análise de situações didáticas que possuam objetivo de criar um cenário de aprendizagem significativa em sala de aula ampliando a sua aplicabilidade para diversas áreas de ensino [7].

Uma das opções de aplicabilidade da Engenharia Didática é no Ensino das Ciências como podemos perceber em publicações disponíveis na literatura das produções científicas $[8,9$, 10]. Esta alternativa de utilização da Engenharia Didática como recurso de investigação em pesquisas no Ensino das Ciências se justifica, pois sua metodologia permite diversas contribuições de pesquisa em ensino, tais como: o diagnóstico das concepções dos sujeitos, um estudo e reflexão sobre as dificuldades e obstáculos de aprendizagem, estudo e análise das estratégias utilizadas pelos estudantes em seus processos de resolução de situações problema e a possível validação de processos de introdução e construção de conhecimentos específicos em situações experimentais e práticas.

A Engenharia Didática tem sua base metodológica estruturada na capacidade de estudar o processo de ensino e aprendizagem a partir da antecipação e previsão de ocorrências, assim como no levantamento das tendências de desenvolvimento de estratégias adotadas pelos estudantes a partir das escolhas convenientes adotadas pelo pesquisador expressas através das variáveis didáticas. O pesquisador desenvolve hipóteses e tenta validá-las pela confrontação das suas expectativas iniciais nas fases antecipatórias da execução prática com as manifestações dos alunos percebidas durante as atividades na fase experimental.

A metodologia da Engenharia Didática é composta por quatro fases as quais podem acontecer em sequência ou até haver etapas em que elas aconteçam em superposição ou articuladas [11].

\subsection{Fase 1: Análises preliminares}

Nesta etapa, o pesquisador se dedica a construção do quadro teórico didático sobre o tema ou conteúdo específico a ser ensinado, valorizando as suas experiências anteriores de ensino. Durante este passo inicial é dedicado um período para uma revisão bibliográfica sobre as pesquisas de ensino do conteúdo ponderando sobre as condições e contextos do ambiente escolar a ser investigado, além de ser necessária uma análise e reflexão sobre os aspectos histórico-epistemológicos dos conteúdos a serem trabalhados avaliando como tem sido ensinado atualmente e como foi ensinado no passado, reconhecer as concepções dos estudantes, os possíveis instrumentos 
e recursos didáticos capazes de serem utilizados, além de prever possíveis dificuldades e obstáculos vivenciados pelos aprendizes durante as atividades de ensino.

\subsection{Fase 2: Concepção e análise a priori das situações didáticas}

Influenciado pelos resultados obtidos nas Análises Preliminares, o pesquisador encaminha e registra as suas escolhas e determina a quantidade de variáveis didáticas que serão pertinentes ao seu sistema de estudo a fim de fundamentar a sua atividade de construção das sequências.

A Análise a priori consiste numa etapa descritiva e preditiva em que, a partir das escolhas de certas variáveis do sistema de ensino que interferem no fenômeno didático, o pesquisador desenvolve o roteiro da situação didática contendo suas expectativas, e planejamento de condutas de acordo com as ocorrências do fenômeno.

Na construção da Situação Didática, o pesquisador deve procurar desenvolver atividades de experimentação em que o estudante seja desafiado a resolver uma situação problema a qual esteja presente, ou que seja possível, a ocorrência de confronto do aluno com os obstáculos cognitivos e/ou conceituais, vivenciar dificuldades e criar situações em que haja a probabilidade de ocorrência de erros previstos na fase da Análise Preliminar [9].

\subsection{Fase 3: Experimentação}

Nesta Etapa é vivenciada a aplicação da sequência didática projetada e construída, além de ser um dos momentos em que o pesquisador faz a sua coleta de dados e executa o registro destas experiências, podendo ser na forma de gravação de áudios, preenchimento de fichas de observação, filmagens dentre outros recursos. A experimentação pode ser composta por uma quantidade de aulas ou sessões, tendo a necessidade de que o professor, no início, realize uma explanação transparente de seus objetivos.

\subsection{Fase 4: Análise a posteriori e a validação}

Esta fase é voltada ao tratamento e análise das informações adquiridas por consequência da aplicação da sequência de ensino na fase de experimentação.

A validação é a etapa na qual o pesquisador realiza uma comparação entre as expectativas declaradas na análise a priori e os elementos apontados na análise a posteriori, a qual qualificamos como validade interna, já que os resultados se limitam ao contexto da experiência realizada. Nesta etapa é realizada a confirmação ou não das hipóteses concebidas na pesquisa.

\section{Metodologia da Pesquisa}

Para a efetivação da investigação pretendida vivenciamos uma sequência de quatro procedimentos metodológicos a partir de elementos da Engenharia Didática Clássica: a
Análise Preliminar, a Análise a Priori, a Experimentação e a Análise a Posteriori e Validação.

\subsection{Sujeitos da pesquisa}

Trabalhamos, inicialmente com um grupo de 14 professores de Física, sendo 12 licenciados e 2 bacharéis, com um tempo médio de experiência de ensino superior de 12 anos. Estes professores participaram apenas da Fase das Análises Preliminares, contribuindo com experiências e percepções sobre as dificuldades de ensino, do conteúdo em questão, e reconhecendo estratégias de resolução de problemas que poderiam ser mobilizadas pelos alunos.

Destacamos que um destes 14 professores participou colaborativamente junto com o pesquisador, que não era professor de física da escola, na condução das atividades de ensino na escola campo de estudo nas três turmas do $1^{\circ}$ Ano do Ensino Médio.

Outro grupo de sujeitos envolvidos na pesquisa consistiu em 87 estudantes pertencentes as três turmas do $1^{\circ}$ Ano do Ensino Médio de uma escola da rede particular localizada na cidade do Recife, em Pernambuco. Estes estudantes vivenciaram as Sequências de Ensino articulando a Robótica Educacional em processos de ensino do fenômeno do Encontro de Corpos em Movimento Uniforme, agrupados em equipes com 3 a 4 componentes, totalizando 24 grupos.

\subsection{Procedimentos metodológicos}

O desenvolvimento da etapa de Análises Preliminares, consistiu em avaliar como se tem ensinado os conteúdos de Encontro de Corpos em Movimento Uniforme e a reconhecer quais as dificuldades e obstáculos que os estudantes vivenciam durante as atividades de ensino. Realizamos um levantamento complementar ao que encontramos exposto na literatura, mediante a aplicação de questionários (APÊNDICE A), através de envio de link de Formulário, a fim de coletamos as percepções e expectativas de 14 professores de Física atuantes em escolas pernambucanas, de Ensino Médio.

Na sequência, desenvolvemos a Etapa da Concepção e Análise a priori da Situação Didática. Durante esta etapa dedicamos um período para o planejamento e a estruturação da Intervenção Didática de Ensino através de três tarefas: Desenvolvimento da Situação Didática, Estruturação da metodologia da Pesquisa e Elaboração dos Instrumentos de coleta de dados. O diagnóstico das concepções dos professores coletadas através dos questionários serviu para ratificação e complementação das percepções e expectativas tanto do pesquisador quanto aquelas sinalizadas na literatura da área. Estas percepções nos motivaram a inserir situações problema nos Testes Diagnóstico e de Avaliação Final (APÊNDICE B) e no Roteiro de Intervenção Experimental (APÊNDICE C) com o objetivo de verificar se os estudantes iriam manifestar tais dificuldades de aprendizagem e que estratégias utilizariam na resolução dos problemas. 
Também nesta etapa, o planejamento da proposta foi apresentado ao professor de Física da escola, das três turmas do $1^{\circ}$ ano do Ensino Médio, que a partir de agora denominamos de professor colaborador.

No planejamento estruturado, o professor colaborador conduziu em sala de aula o ensino do conteúdo Movimento Uniforme e suas aplicações, apresentou os problemas de Encontro de Corpos em Movimento Uniforme com a resolução de questões de Vestibulares durante duas semanas, através de processos de ensino usualmente adotados por ele. Este professor não participou da elaboração dos Testes e do Roteiro de Intervenção Experimental propositadamente, de forma a evitar qualquer direcionamento prévio.

A etapa da Experimentação da Situação Didática desenvolvida consistiu em três procedimentos: a aplicação de um Teste Diagnóstico, na vivência da sequência de ensino experimental e na aplicação de um Teste de Avaliação Final.

Trabalhamos com 97 alunos distribuídos em três turmas. Após o momento de ensino e resolução de problemas realizado pelo professor de Física da escola, aplicamos o Teste Diagnóstico em cada turma em sessões de 50 minutos.

Diante da dificuldade de trabalhar com todos os alunos de uma turma, em torno de 32 alunos, na sequência de ensino experimental utilizando a Robótica Educacional decidimos dividir a turma em 2 grupos adotando a ordem alfabética como critério para a montagem dos grupos. Realizamos as atividades em 2 dias de aula executando um revezamento destes dois grupos. No primeiro dia, metade dos estudantes da turma ficou em sala de aula com o professor de Física resolvendo questões e tirando dúvidas, enquanto a outra metade acompanhada pelo pesquisador, dividida em 4 equipes de 4 componentes, realizava a parte experimental. Cada equipe ficou responsável pela montagem de um carro robô, e em seguida vivenciarem a experimentação, em sessões de 100 minutos equivalente a 2 aulas de 50 minutos. Para atender a dinâmica experimental do Encontro de Corpos e trabalhar com as quatro equipes ao mesmo tempo, montamos duas pistas, cada uma atendendo dois carros robôs. Na semana seguinte, executamos as atividades de forma invertida.

Após três semanas decorridas do evento das vivências da sequência de ensino experimental, aplicamos o Teste de Avaliação Final em cada turma, em sessões de 50 minutos. As análises dos dados consideraram apenas os sujeitos que vivenciaram as três etapas da experimentação. Desta forma a amostra final consistiu em 87 alunos.

Vale salientar que a aplicação dos Testes Diagnósticos e dos Testes de Avaliação Final não tiveram o objetivo de servir como um pré-teste e pós-teste na pesquisa, com a finalidade de verificação de melhorias no índice de acerto das questões. A proposta da sequência de ensino a partir de elementos da Engenharia Didática foi a de desenvolver uma dinâmica didática de ensino que conseguisse mobilizar saberes e reconhecer dificuldades e obstáculos na resolução de problemas, assim como buscar elementos de apoio ao professor no ensino do conteúdo trabalhado.

Assim, os resultados dos testes serviram para o reconhecimento das dificuldades de construções de conceitos, das estratégias competentes e das estratégias desconectadas de lógica científica utilizadas na solução dos problemas, externadas antes (Teste Diagnóstico) e após a experimentação (Teste de Avaliação Final) evidenciando o amadurecimento do estudante e a significação acrescentada pela experiência com a atividade utilizando a Robótica..

Após a aplicação do Teste Diagnóstico e do Teste de Avaliação Final, fizemos a sua correção e inserção destes resultados em uma planilha eletrônica para efeito de análise estatística e reconhecimento das tendências, contemplando as últimas etapas da Engenharia Didática: a Análise a Posteriori e a Validação.

\subsection{Instrumentos da pesquisa}

Foram desenvolvidos quatro instrumentos de coleta de informações: Questionário sobre as percepções dos professores, Roteiro da Atividade Experimental, Teste Diagnóstico e Teste de Avaliação Final.

Tanto o Teste Diagnóstico quanto o Teste de Avaliação Final foram compostos por 6 questões com a intenção de identificar as estratégias utilizadas pelos estudantes na resolução de questões com o fenômeno de Encontro de Corpos e reconhecimento de habilidades desenvolvidas referentes ao Movimento Uniforme.

A Questão 1 dos Testes pedia para que o estudante definisse com as suas palavras o conceito de Movimento Uniforme. A Questão 2 solicitava para que o aluno identificasse dentre quatro movimentos descritos, através de suas posições e instantes exibidos em uma tabela, quais deles representavam um Movimento Uniforme, como ilustrado na Tabela 1. A intenção destas duas questões era identificar se o sujeito da pesquisa conseguia além de definir corretamente o conceito de Movimento Uniforme também se conseguia aplicá-lo e identificar os dados do espaço versus tempo que expressavam um corpo em Movimento Uniforme. Foi colocado em um dos 4 casos de movimento, precisamente no corpo 3 , uma situação de repouso no qual as posições do corpo permaneciam, em todos os instantes, com a mesma posição. Daí, existe a possibilidade de o estudante confundir a situação de posição constante com o de um Movimento Uniforme.

A Questão 3 buscou identificar se o aluno conseguia, a partir de um texto contextualizado com diversas infor-

Tabela 1: Recorte da tabela de Movimentos de 4 corpos contida no Teste Diagnóstico

\begin{tabular}{lccccccccc}
\hline $\mathrm{S}_{1}(\mathrm{~m})$ & 1 & 4 & 9 & 16 & 25 & 36 & 49 & 64 & 81 \\
\hline $\mathrm{S}_{2}(\mathrm{~m})$ & 5 & 10 & 15 & 20 & 25 & 30 & 35 & 40 & 45 \\
\hline $\mathrm{S}_{3}(\mathrm{~m})$ & 8 & 8 & 8 & 8 & 8 & 8 & 8 & 8 & 8 \\
\hline $\mathrm{S}_{4}(\mathrm{~m})$ & 18 & 16 & 14 & 12 & 10 & 8 & 6 & 4 & 2 \\
\hline $\mathrm{t}(\mathrm{s})$ & 1 & 2 & 3 & 4 & 5 & 6 & 7 & 8 & 9 \\
\hline
\end{tabular}


mações disponíveis, determinar a velocidade média de um corpo, expressa em quilômetros por hora $(\mathrm{km} / \mathrm{h})$ a partir da disponibilização da distância percorrida, com sua unidade de medida de comprimento diferente do Sistema Internacional de Unidades (SI), e do intervalo de tempo decorrido. Esperamos que alguns sujeitos da pesquisa encontrassem dificuldades nas transformações de unidades de comprimento, assim como na conversão da unidade da velocidade média de metros por segundo $(\mathrm{m} / \mathrm{s})$ para quilômetros por hora $(\mathrm{km} / \mathrm{h})$.

A Questão 4 consistia em uma situação de Encontro de Corpos com dois corpos em movimentos uniformes de oposição representados através de uma figura informando suas respectivas velocidades em módulo, seus sentidos e suas posições iniciais em uma trajetória retilínea orientada.

A Questão 5 apresentou uma situação de Encontro de Corpos em Movimento Uniforme com as equações horárias de espaço de cada corpo e questionava qual o instante em que o corpo A conseguiria a ultrapassagem. Colocamos uma situação em que, diante das condições iniciais, o corpo A nunca ultrapassaria o corpo B, pois este já estava na frente e era mais rápido que o corpo B. Esperava-se que o estudante respondesse que não haveria encontro nem ultrapassagem. Caso utilizasse a estratégia de igualar as equações horárias, encontrando um instante negativo, deveria interpretar o significado do valor de tempo negativo e reconhecer que não haveria ultrapassagem.

Na Questão 6 colocamos uma situação de Encontro de Corpos em Movimento Uniforme na qual disponibilizamos os valores das velocidades de cada corpo e seus sentidos, além da informação sobre a distância entre eles na situação inicial no texto do enunciado. Nesta Questão pedimos que o estudante procurasse a determinação do instante e da posição de encontro dos corpos.

\section{Análise e Discussão dos Resultados}

Na Análise Preliminar, conseguimos elencar, com o auxílio do Questionário aplicado com os 14 professores de física, algumas possíveis dificuldades dos estudantes, elencadas na Tabela 2. Estas foram consideradas no desenho do Teste Diagnóstico e Teste de Avaliação Final, bem como para o desenho da sequência de ensino, as situações foram propostas com o intuito de evidenciar domínio do conteúdo e superação dos obstáculos identificados.

Após a coleta de dados e análise dos desempenhos dos 87 estudantes nos Testes Diagnósticos e nos Testes de Avaliação Final, definimos onze variáveis, associadas as questões que compõem os testes, que estão elencadas na Tabela 3.

A Engenharia Didática pressupõe que as aprendizagens não são pontuais nem lineares, muitas vezes é preciso descontruir concepções e ideias pré-estabelecidas sobre o movimento para então reconstruí-las numa perspectiva mais próxima da científica. As analises a partir da di-
Tabela 2: Detalhamento das dificuldades e obstáculos na resolução dos problemas mapeados na etapa de Análise Preliminar Dificuldades e Obstáculos

\begin{tabular}{l}
\hline Ao igualar as funções horárias dos móveis e encontrar um \\
instante de encontro negativo, o estudante pode não identificar \\
que não haverá a ultrapassagem, pois, o corpo que está mais \\
atrás não possui velocidade capaz de ultrapassagem. \\
\hline Dificuldade de resolver uma equação do $1^{\circ}$ grau, se compli- \\
cando e não conseguindo isolar corretamente a incógnita da \\
equação. \\
\hline O estudante pode não conseguir representar o movimento dos \\
corpos através das suas funções horárias de espaço. \\
\hline O aluno pode cometer erro na resolução caso não converta, \\
ou converta de forma errada, as grandezas envolvidas (espaço, \\
velocidade e tempo de estudo do movimento dos corpos para \\
um mesmo sistema de unidades). \\
\hline Dificuldade em relação a leitura dos enunciados das questões, \\
o que compromete a interpretação física do problema. \\
\hline Desconsiderar a atribuição de sinal da velocidade de acordo \\
com o seu sentido diante da trajetória adotada (referencial \\
adotado).
\end{tabular}

nâmica entre as variáveis é mais complexa e justamente por isso, reflete de forma mais fidedigna, o processo de aprendizagem dos conceitos científicos. Ao contrário dos índices percentuais de acertos de questões em pré e pós testes.

Emitimos para cada estudante participante, através do desenvolvimento de um documento de mala direta do editor de texto Word, composto a partir do tratamento estatístico dos dados coletados, um Relatório Devolutivo Individual (APÊNDICE D). A entrega deste parecer ao estudante teve o objetivo de informá-lo sobre como foi a sua performance, detalhando as habilidades manifestadas, suas lacunas conceituais e a detecção de seus obstáculos na resolução de problemas, além das respostas esperadas e dos objetivos para cada questão. Acreditamos que estas informações possibilitam uma oportunidade de investimento na correção dos equívocos e erros cometidos, no reconhecimento de estratégias mais adequadas, além de refletir sobre o seu processo de estudo e aprendizagem.

Outro mecanismo de monitoramento do processo de ensino e aprendizagem da sequência de ensino, implementado e concebido durante o transcurso da nossa pesquisa, consistiu em um instrumento de retorno, para o professor colaborador, dos resultados obtidos pelos estudantes e percentuais de uso das estratégias categorizadas para a solução dos problemas de Encontro de Corpos. Nosso objetivo foi contribuir na revisão dos processos de ensino, possibilitando o desenvolvimento de ações e o planejamento de estratégias complementares de ensino a fim de que estes alunos superassem tais dificuldades, diminuindo a incidência de equívocos e a manifestação de estratégias inadequadas. Este instrumento de apoio ao professor colaborador da escola, na forma de parecer sobre o desempenho global dos estudantes e das turmas, foi nomeado como Relatório Devolutivo Coletivo (APÊNDICE D).

Comparando a performance de percentual de acertos dos estudantes, expresso pela variável V1 exibida na 
Tabela 3: Percentuais de utilização das Estratégias identificadas nos testes

\begin{tabular}{llcc}
\hline Variáveis & \multicolumn{1}{c}{ Descrição } & Teste Diagnóstico & Teste Avaliação Final \\
\hline V1 & Percentual de acertos no Teste & $44,9 \%$ & $59,3 \%$ \\
\hline V2 & Define Movimento Uniforme corretamente (Questão 1) & $73,6 \%$ \\
\hline V3 & Identifica Movimento Uniforme de forma correta (Questão 2) & $48,8 \%$ & $37,9 \%$ \\
\hline V4 & $\begin{array}{l}\text { Confunde posição constante com um caso de Movimento Uniforme } \\
\text { (Questão 2) }\end{array}$ & $40,2 \%$ & $49,4 \%$ \\
\hline V5 & Determina a Velocidade Média corretamente (Questão 3) & $42,5 \%$ \\
\hline V6 & $\begin{array}{l}\text { Erra em transformação de unidades no cálculo da velocidade média } \\
\text { (Questão 3) }\end{array}$ & $46,0 \%$ & $56,3 \%$ \\
\hline V7 & $\begin{array}{l}\text { Utiliza a convenção de velocidade negativa quando o corpo está com } \\
\text { sentido oposto a orientação da trajetória (Questão 4) }\end{array}$ & $48,3 \%$ & $60,9 \%$ \\
\hline V8 & $\begin{array}{l}\text { Acerta Questão de Encontro de Corpos com movimento opostos a } \\
\text { partir da Figura representativa (Questão 4) }\end{array}$ & $42,5 \%$ & $56,3 \%$ \\
\hline V9 & $\begin{array}{l}\text { Demonstra não saber o significado do resultado de tempo negativo } \\
\text { no Encontro de Corpos (Questão 5) }\end{array}$ & $70,1 \%$ & $57,5 \%$ \\
\hline V10 & $\begin{array}{l}\text { Reconhece a não ultrapassagem quando o corpo mais veloz se } \\
\text { encontra a frente do mais lento (Questão 5) }\end{array}$ & $6,9 \%$ & $39,1 \%$ \\
\hline V11 & $\begin{array}{l}\text { Acerta Questão de Encontro de Corpos com os valores e sentidos } \\
\text { das velocidades e a distância entre os corpos expressos no enunciado } \\
\text { (Questão 6) }\end{array}$ & $52,9 \%$ & $93,1 \%$ \\
& & & 49 \\
\hline
\end{tabular}

Tabela 3, constatamos um crescimento de $44,9 \%$ para $59,3 \%$. Tal crescimento era esperado uma vez que estavam imersos em estudos sobre o Movimento Uniforme e o fenômeno do Encontro de Corpos em Movimento Uniforme em sala de aula em situações didáticas mediadas pelo professor colaborador e o pesquisador. Contudo, nossas expectativas eram maiores, esperávamos que estes sujeitos manifestassem o uso de estratégias mais competentes nas situações problemas e reestruturassem melhor suas concepções ampliando suas habilidades de conceituar o Movimento Uniforme e de resolver corretamente os problemas propostos.

Para entender os motivos pelos quais os resultados não foram melhores, convém uma análise mais detalhada das dificuldades observadas. Por exemplo, as variáveis V2, V3 e V4 na Tabela 3, verificadas através das Questões 1 e 2, evidenciam que uma boa parcela de estudantes, cerca de 49,3\% (V4), chega ao final do estudo confundindo a constância dos valores da posição no decorrer do tempo com as situações de Movimento Uniforme. Na Questão 2 o recomendável é que o estudante, em cada situação (cada conjunto de dados contido na linha da Tabela 1) execute inicialmente o cálculo da velocidade média específica para cada intervalo de tempo, dividindo a variação de espaço pelo intervalo de tempo decorrido, e verifique se este valor de velocidade média calculado permanece constante e diferente de zero.

Desta forma percebemos que muitas vezes o estudante consegue compreender e enunciar corretamente o conceito científico do Movimento Uniforme (MU), verificado pelo crescimento no índice V2, que passa de $59,8 \%$ para $73,6 \%$, mas não consegue utilizar conceito adequadamente para identificar corretamente as situações de Movimento Uniforme evidenciado pelos resultados da variável V3 que diminui de $48,3 \%$ para $37,9 \%$, ao final do estudo.

A partir da situação descrita, observamos claramente a dinâmica entre variáveis, mencionada anteriormente.
Ao considerarmos V2, V3 e V4, poderíamos pensar em um primeiro momento, a partir da observação de V2 que houve uma melhoria na aprendizagem do conceito, contudo, a queda percentual de V3 e o aumento percentual de V4, indicam que, após a intervenção, as dificuldades ficaram ainda mais evidentes. Se considerarmos que essas dificuldades têm origem nas teorias implícita dos sujeitos, era esperado, que não fossem facilmente superadas.

Outra questão na qual observamos indicativos de dificuldades de compreensão e de domínio matemático, foi a Questão 3, que buscava reconhecer a competência de calcular a velocidade média. As dificuldades surgem na execução das transformações de unidades de medidas de comprimento e da velocidade, representadas pela variável V6. Neste caso, chegamos ao final do estudo com um aumento percentual nas ações incorretas nas transformações de unidades das grandezas envolvidas de 46,0\% para $56,3 \%$.

Os índices obtidos para as variáveis V3 e V6 ao final do estudo, sinalizam a necessidade de um esforço complementar no trabalho docente que oportunize aos estudantes a superação destas dificuldades e desenvolva habilidades competentes nas transformações de unidades de medidas e na identificação de situações de corpos em Movimento Uniforme.

Com relação as Questões 4, 5 e 6 dos testes, que tinham como objetivos reconhecer a habilidade dos sujeitos em encontrar o instante de encontro dos móveis nas situações problema de Encontro de Corpos, visualizamos resultados de percentuais de acertos nas questões, expressos através das variáveis V8, V10 e V11, com um bom índice de crescimento. Esta elevação evidência que, após a vivência das experiências formativas, estes estudantes se utilizaram de estratégias mais competentes.

Na fase das Análises Preliminares, conseguimos reconhecer três estratégias diferentes possíveis, para se chegar 
a encontrar a solução do desafio do Encontro de Corpos proposto nas Questões 4, 5 e 6.

A Estratégia 1 consiste na construção das Equações Horárias de Espaço de cada corpo e igualar as suas funções horárias, que significa a condição em que os móveis ocupam a mesma posição, determinando o instante de encontro.

Para clarificar a Estratégia 1, aproveitamos a resolução de um dos sujeitos participantes da pesquisa referente a Questão 4 do Teste Diagnóstico, ilustrada na Figura $1(\mathrm{a})$.

Como verificamos, inicialmente o estudante expressou a Equação Horária do Espaço do corpo A $\left(\mathrm{S}_{\mathrm{A}}=10+\right.$ $10 \mathrm{t})$ e a do corpo $\mathrm{B}\left(\mathrm{S}_{\mathrm{B}}=80-25 \mathrm{t}\right)$, notando que o sinal corretamente convencionado da velocidade do corpo B de $25 \mathrm{~m} / \mathrm{s}$ foi negativo, pois estava com o sentido oposto ao da orientação da trajetória. Após a montagem das duas equações horárias do espaço dos móveis, ele igualou as duas equações e obteve uma equação do $1^{\circ}$ grau com uma incógnita, ao isolar o tempo, chegou ao instante de encontro dos corpos igual a 2 segundos.

A Estratégia 2 consiste na utilização do conceito da Velocidade Relativa. A Velocidade Relativa do corpo é obtida através da soma das velocidades dos móveis, caso as velocidades dos corpos em relação ao solo estejam em sentidos opostos, e pela subtração das velocidades dos móveis, caso as velocidades dos corpos em relação ao solo estejam no mesmo sentido. Após tal procedimento, o aluno calcula o tempo necessário para o encontro, dividindo a distância entre eles pela velocidade relativa calculada, como visualizamos na Figura 1(b).
Como podemos perceber, inicialmente o estudante calculou corretamente a velocidade relativa através da soma das velocidades $\left(\mathrm{V}_{\mathrm{R}}=10 \mathrm{~m} / \mathrm{s}+25 \mathrm{~m} / \mathrm{s}=35 \mathrm{~m} / \mathrm{s}\right)$ já que os dois móveis estavam com velocidades em sentidos opostos. Outro parâmetro calculado foi a distância entre os corpos, tendo sido encontrado o valor de $70 \mathrm{~m}$, decorrente da diferença entre a posição do corpo B e a do corpo $\mathrm{A}(\Delta \mathrm{S}=80 \mathrm{~m}-10 \mathrm{~m}=70 \mathrm{~m})$. Ao final, encontrou o instante de encontro de $2 \mathrm{~s}$, através da divisão da distância entre os corpos obtida $(\Delta \mathrm{S}=70 \mathrm{~m})$ pela velocidade relativa calculada $\left(\mathrm{V}_{\mathrm{R}}=35 \mathrm{~m} / \mathrm{s}\right)$.

A Estratégia 3 consiste na construção de uma tabela ou de um gráfico com os valores do espaço do movimento a partir de suas leituras, durante o registro de sua vivência experimental, a fim de induzir a tendência de intersecção dos valores de espaços obtidos. Este procedimento tem limitações e dificuldades em sua determinação, principalmente quanto o instante de encontro não é um valor inteiro.

Ilustramos a Estratégia 3, na Figura 1(c). O diagrama expressa uma reta orientada com o registro da indução de espaço ocupado pelos corpos no decorrer do tempo. Observamos que o estudante representa inicialmente as posições ocupadas nos instantes $\mathrm{t}=1 \mathrm{~s}$ e $\mathrm{t}=2 \mathrm{~s}$ pelo corpo A (20m e $30 \mathrm{~m}$, pois o corpo A possui velocidade de $10 \mathrm{~m} / \mathrm{s}$ e a cada $1 \mathrm{~s}$ ele acrescenta $10 \mathrm{~m}$ ao seu espaço anterior) e o corpo B $(55 \mathrm{~m}$ e $30 \mathrm{~m}$, pois o corpo B possui velocidade de $25 \mathrm{~m} / \mathrm{s}$ e a cada 1 s ele diminui $25 \mathrm{~m} \mathrm{em}$ relação ao seu espaço anterior). Logo ele percebeu que os dois corpos, após $2 \mathrm{~s}$, coincidem as suas posições no espaço $30 \mathrm{~m}$.

4. Dois carros estão sobre a mesma trajetória, logo com mesma direção, porém, com sentidos opostos e velocidades de $10 \mathrm{~m} / \mathrm{s}$ e $25 \mathrm{~m} / \mathrm{s}$ respectivamente. Encontre o instante de encontro entre os móveis A e B.

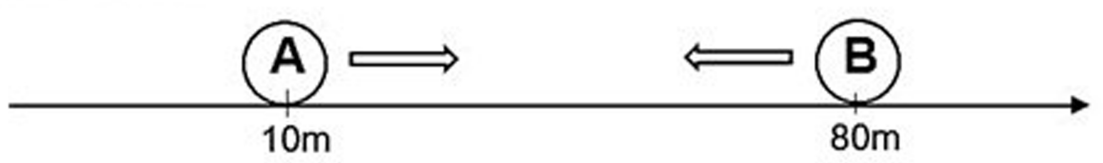

(a) Estratégia 1

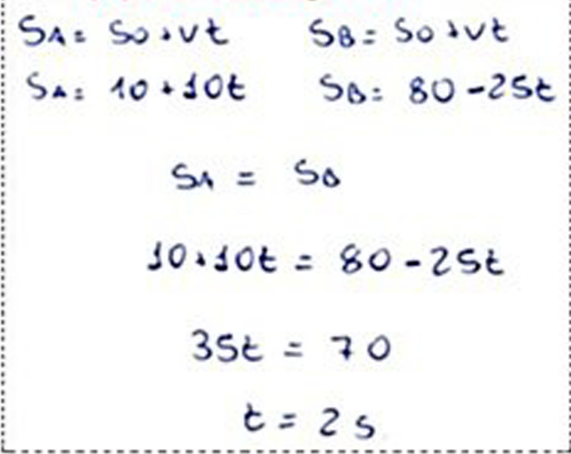

(b) Estratégia 2

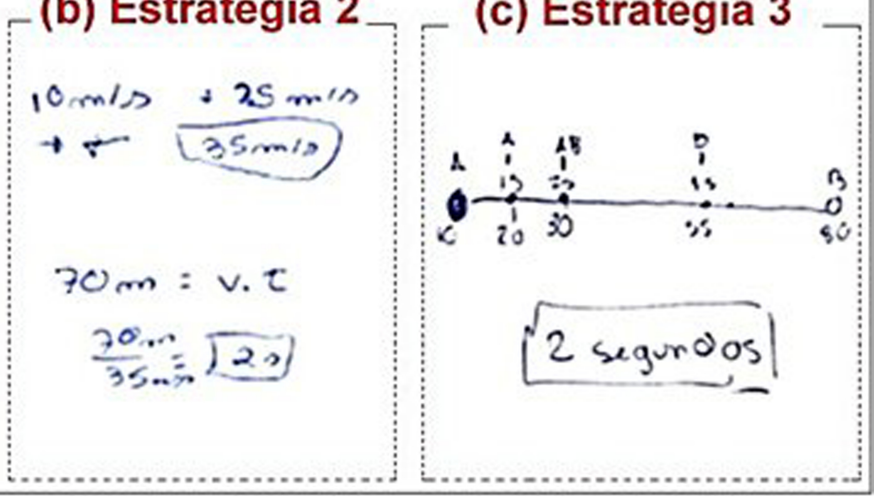

Figura 1: Recorte de resolução da Questão 4 do Teste Diagnóstico utilizando a (a) Estratégia 1 (b) Estratégia 2 (c) Estratégia 3 , utilizadas por estudantes participantes. 
Quando analisamos o desempenho dos estudantes ao encontrar um instante de encontro dos corpos com valor negativo, muitos expressaram suas respostas utilizando o valor negativo, ou simplesmente positivaram o seu resultado. Este tipo de resposta a Questão 5 sinaliza que o aluno desconhece o significado do resultado do tempo negativo, expresso pela variável V9, que teve um alto índice de ocorrência no Teste Diagnóstico chegando a $70,1 \%$. Apesar do percentual relativo a esta variável ter sido reduzido para 57,5\% no Teste de Avaliação Final, consideramos ainda um resultado expressivo e sinalizamos a necessidade de um trabalho docente complementar para tentar explicitar ao estudante o verdadeiro significado deste resultado. Esta dificuldade de entendimento do significado do tempo de encontro negativo, também foi evidenciada em função do baixo valor percentual de acerto na Questão 5, variável V10, no Teste Diagnóstico, com apenas $6,9 \%$ dos estudantes indicando que não haveria a ultrapassagem. Já nos resultados obtidos no Teste da Avaliação Final, o percentual de acerto cresceu e alcançou 39,1\%. Percebemos que a exposição da situação descrita com a ocorrência de tempo negativo no Teste Diagnóstico, foi importante para o planejamento da vivência experimental, aspecto que pode ter influenciado positivamente os índices do Teste de Avaliação Final, relativos aos estudantes que conseguiram detectar a não ocorrência da ultrapassagem, sem sequer precisar utilizar a estratégia de igualar as equações horárias de espaço dos corpos.

Quando da resolução da situação problema de Encontro de Corpos em Movimento Uniforme necessário nas questões 4, 5 e 6 dos Testes, os estudantes utilizaram diferentes estratégias para a solução do problema proposto. Inicialmente tínhamos reconhecido apenas três estratégias. Porém, na análise dos resultados obtidos nos Testes, identificamos mais 6 (seis) estratégias que os alunos utilizaram, as quais levaram ou não ao acerto na determinação do instante de Encontro dos Corpos.

Um aspecto importante percebido no uso das estratégias de resolução dos problemas de Encontro de Corpos em Movimento Uniforme foi a importância da atribuição correta do sinal da velocidade dos corpos em movimento, de acordo com a orientação da trajetória adotada. Um erro de atribuição do sinal da velocidade leva a um resultado do instante de encontro dos móveis incorreto. As análises indicaram que a utilização correta do sinal negativo da velocidade para os casos de corpos em movimento retrógrado, expressos pela variável V7, cresceu de 48,3\% para $60,9 \%$, apontando um amadurecimento conceitual e maior possibilidade de sucesso na execução da estratégia apropriada para encontrar o instante de encontro dos corpos.

Das 9 (nove) estratégias identificadas nos testes, apenas 4 (quatro) delas conseguem levar o aluno ao resultado correto: Estratégias 1, 2, 3 e 4. As Estratégias 1, 2 e 3 já foram explicitadas e tinham sido previstas no estudo da Análise Preliminar, mas a Estratégia 4 só foi identificada após a sua utilização no Teste de Avaliação Final. Ela só se aplica na situação da Questão 5, que posiciona o corpo mais veloz a frente do mais lento no instante inicial. A Estratégia 4 consiste na percepção de que se móvel mais veloz está mais a frente no instante inicial, não haverá possibilidade de ultrapassagem. Os percentuais de estudantes que empregaram a Estratégia 4 na Questão 5 , cresceu de $5 \%$ para $20 \%$, fato que aponta que os estudantes ficaram mais atentos à situação e perceberam a impossibilidade de ultrapassagem, sem sequer executar qualquer tipo de cálculo matemático para chegar a esta conclusão.

As demais estratégias adotadas pelos alunos nos testes, e identificadas como Estratégias 5, 6, 7, 8 e 9, não levaram os estudantes a determinarem o instante de encontro dos corpos correto e não tinham sido previstas na etapa de Análise Preliminar.

Categorizamos como Estratégia 5 o processo em que o estudante calculou os tempos necessários para cada um dos corpos percorrer a distância inicial entre os móveis, com a sua velocidade correspondente. De posse destes dois tempos calculados, atribuiu o instante de encontro dos corpos como sendo a subtração destes dois tempos calculados. Exemplificando, como podemos ver na Figura 2, que representa um recorte da Questão 4, do Teste Diagnóstico, reconhecemos que a distância inicial entre os corpos é de 70 metros. Alguns estudantes calcularam o tempo do corpo A como sendo a distância inicial entre os corpos dividido pela velocidade do corpo A, obtendo $70 \div 10$ igual a $t_{A}=7$ s. O tempo do corpo $\mathrm{B}$ como sendo a distância de $70 \mathrm{~m}$ dividido por sua velocidade de $25 \mathrm{~m} / \mathrm{s}$, obtendo $70 \div 25$ igual a $\mathrm{t}_{\mathrm{B}}=2,8 \mathrm{~s}$. De posse dos tempos individuais, estes estudantes atribuíram o instante de encontro dos corpos como sendo a subtração destes dois valores, ou seja, $\mathrm{t}=\mathrm{t}_{\mathrm{A}}-\mathrm{t}_{\mathrm{B}}=7-2,8=$ $4,2 \mathrm{~s}$.

Percebemos que um percentual de $6 \%$ e $5 \%$ dos estudantes chegaram a utilizar a Estratégia 5 nas questões 4 e 6 do Teste Diagnóstico, respectivamente. Porém, esta estratégia incorreta foi quase que abandonada no Teste de Avaliação Final, como indicam os índices de utilização desta estratégia que indicam nenhum uso (0\%) nas questões 4 e 5 e um percentual de $1 \%$ na Questão 6. Após um período de formação de conceitos e estruturação do saber, era esperado que o estudante reestruturasse as suas estratégias. Observamos uma ampliação do uso da Estratégia 1, em distintos contextos do fenômeno de Encontro de Corpos, na Questão 4, por exemplo, seu uso cresceu de $40 \%$ para $87 \%$, enquanto na Questão 6, passou de $49 \%$ para $77 \%$.

Denominamos a Estratégia 6 como sendo o processo em que o estudante calcula os tempos necessários para cada corpo vencer a distância entre eles em função de sua velocidade correspondente, similar a Estratégia 5, e posteriormente somá-los. Detectamos tal utilização apenas na Questão 4, do Teste Diagnóstico, com índice percentual de $6 \%$, porém tal estratégia foi descartada 


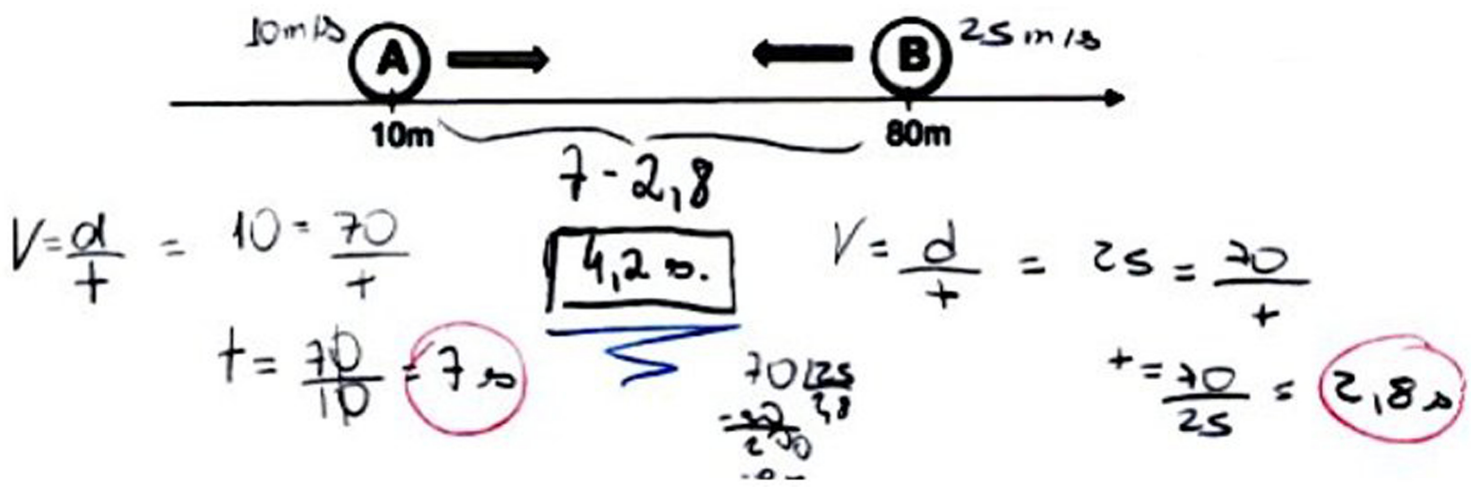

Figura 2: Recorte de resolução da Questão 4 do Teste Diagnóstico utilizando a Estratégia 5 empregada por alguns estudantes participantes.

totalmente no Teste de Avaliação Final, como esperado diante da percepção do erro provocado quando da sua aplicação.

A Estratégia 7 considera o processo adotado pelo aluno na resolução do problema no qual ele calcula os tempos individuais, similar a Estratégia 5, e atribui o instante de encontro dos corpos resultado da média aritmética entre estes tempos individuais calculados. Visualizamos que esta estratégia só foi empregada por um grupo reduzido de estudantes, $3 \%$ dos sujeitos participantes, exclusivamente na Questão 4, do Teste Diagnóstico, sendo posteriormente descartada nas Questões de Encontro de Corpos, no Teste de Avaliação Final.

A Estratégia 8 considera o procedimento em que o estudante após achar os tempos individuais ou apenas um deles, similar a Estratégia 5, determina o instante de encontro dos corpos como sendo um dos tempos encontrados, sem nos revelar qual a sua lógica de escolha. Tal estratégia chegou a ser utilizada amplamente nas questões de Encontro de Corpos do Teste Diagnóstico, e ainda foi mobilizada, com índices mais reduzidos, nas Questões 4 e 6, do Teste de Avaliação Final. Esta estratégia indica que o estudante não tem domínio da lógico e compreensão dos procedimentos que está executando e decide por alguma estratégia que o leve a obter qualquer resultado, mesmo sem saber o seu significado.

Em função de termos encontrado na resolução do problema de Encontro de Corpos, precisamente nas Questões 4,5 e 6 , procedimentos de resolução sem condições de detecção de uma lógica e significado compreensível, eles foram categorizados como sendo a Estratégia 9.

Como podemos perceber na Tabela 4, as estratégias utilizadas pelos estudantes na resolução dos problemas de Encontro de Corpos sofreram alterações evidenciando uma tendência dos alunos a se utilizarem da Estratégia 1, abandonando alguns procedimentos incorretos. Acreditamos que tal fato se deve principalmente as etapas de vivência experimental e as atividades realizadas na sala de aula pelo professor colaborador, que trabalhou diversas estratégias de resolução de problemas utilizando sua própria metodologia de ensino.
Na vivência da sequência de ensino experimental do fenômeno de Encontro de Corpos em Movimento Uniforme, utilizando o kit de Robótica Educacional, inicialmente apresentamos o desafio da simulação do Encontro de Corpos com dois robôs a serem montados por eles. Cada equipe, composta por até quatro integrantes, ficaram com a responsabilidade da montagem de um carro robô com esteira seguindo um Guia de Montagem disponibilizado como exibido na Figura 3. A escolha do carro com esteira foi devido a facilidade com que este modelo consegue andar em linha reta e sua aderência sem deslizamento o que facilita, do ponto de vista experimental, conservar o carro com velocidade constante e mantê-lo em trajetória retilínea.

Com a conclusão da programação dos carros, cada equipe foi orientada a posicionar o seu carro robô na pista orientada por uma fita métrica e executar as leituras do tempo decorrido pelo robô, através do aplicativo de cronômetro disponível em seus aparelhos celulares, em cada um dos quatro trechos de $30 \mathrm{~cm}$, marcados com riscos vermelhos no piso da sala junto a fita métrica como visualizado na Figura 4.

A dinâmica de levantamento destes dados de leitura experimental consistiu na realização de três eventos e

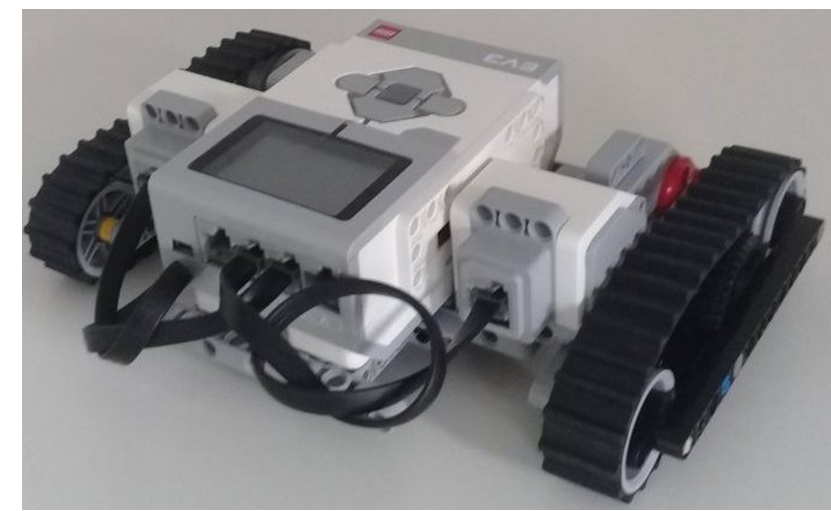

Figura 3: Carro robô montado na experimentação 
Tabela 4: Percentuais de utilização das Estratégias identificadas nos testes

\begin{tabular}{|c|c|c|c|c|c|c|}
\hline \multirow{2}{*}{ Estratégias } & \multicolumn{2}{|c|}{$\begin{array}{c}\text { Questão 4: } \\
\text { Representação Gráfica }\end{array}$} & $\begin{array}{c}\text { Questão 5: } \\
\text { Não ocorre ultrapassagem }\end{array}$ & \multicolumn{3}{|c|}{$\begin{array}{c}\text { Questão 6: } \\
\text { Dados fornecidos no Enunciado }\end{array}$} \\
\hline & $\begin{array}{c}\text { Teste } \\
\text { Diagnóstico }\end{array}$ & $\begin{array}{l}\text { Teste Avaliação } \\
\text { Final }\end{array}$ & $\begin{array}{c}\text { Teste } \\
\text { Diagnóstico }\end{array}$ & $\begin{array}{l}\text { Teste Avaliação } \\
\text { Final }\end{array}$ & $\begin{array}{c}\text { Teste } \\
\text { Diagnóstico }\end{array}$ & $\begin{array}{c}\text { Teste Avaliação } \\
\text { Final }\end{array}$ \\
\hline 1 & $40 \%$ & $87 \%$ & $67 \%$ & $70 \%$ & $49 \%$ & $77 \%$ \\
\hline 2 & $14 \%$ & $7 \%$ & $3 \%$ & $6 \%$ & $14 \%$ & $8 \%$ \\
\hline 3 & $8 \%$ & $3 \%$ & $1 \%$ & $0 \%$ & $3 \%$ & $3 \%$ \\
\hline 4 & $6 \%$ & $0 \%$ & $1 \%$ & $0 \%$ & $5 \%$ & $1 \%$ \\
\hline 5 & $6 \%$ & $0 \%$ & $0 \%$ & $0 \%$ & $0 \%$ & $0 \%$ \\
\hline 6 & $3 \%$ & $0 \%$ & $0 \%$ & $0 \%$ & $0 \%$ & $0 \%$ \\
\hline 7 & $8 \%$ & $1 \%$ & $3 \%$ & $0 \%$ & $7 \%$ & $2 \%$ \\
\hline 8 & $8 \%$ & $1 \%$ & $2 \%$ & $1 \%$ & $3 \%$ & $1 \%$ \\
\hline 9 & $0 \%$ & $0 \%$ & $5 \%$ & $20 \%$ & $0 \%$ & $0 \%$ \\
\hline Em Branco & $7 \%$ & $0 \%$ & $17 \%$ & $3 \%$ & $18 \%$ & $7 \%$ \\
\hline
\end{tabular}

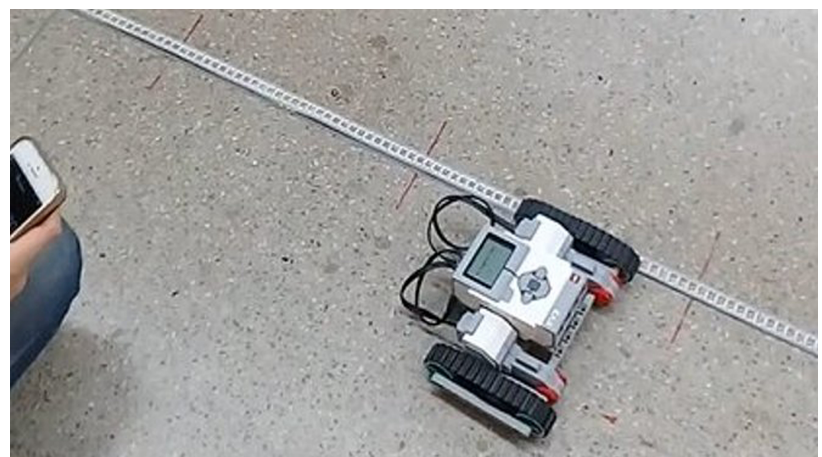

Figura 4: Detalhe do carro robô se deslocando para determinação da velocidade

consideração do valor médio das leituras, na tentativa de diminuir as imprecisões das medidas de tempo efetuadas.

Após a determinação da velocidade de cada carro robô, as duas equipes vivenciaram etapa de experimentação, da ocasião de Encontro de Corpos em sentidos opostos, através de uma situação concreta e real. Ou seja, um dos robôs, precisamente o carro A, foi posicionado com a sua parte mais extrema a frente (ponta da esteira da roda) na posição Zero $(0 \mathrm{~cm})$ do lado direito da pista orientada com a fita métrica e o outro robô, o carro B, foi colocado com a sua parte extrema dianteira na posição $100 \mathrm{~cm}$ no lado esquerdo da fita métrica no sentido de movimento oposto ao carro A, como ilustrado na Figura 5.

A proposição da situação de Encontro dos corpos em movimentos opostos foi dividida em dois momentos: um inicial no qual as equipes iriam coletar experimentalmente o instante e a posição de encontro dos corpos e o outro momento dedicado a determinação do instante e a posição de encontro através de métodos físicos e matemáticos, utilizando as estratégias de resolução do problema descritas anteriormente. O objetivo de vivenciar estes dois momentos foi comparar os resultados experimentais com os resultados matemáticos e refletir sobre possíveis discrepâncias.

Para execução das leituras experimentais tivemos que dividir responsabilidades entre os participantes tentando

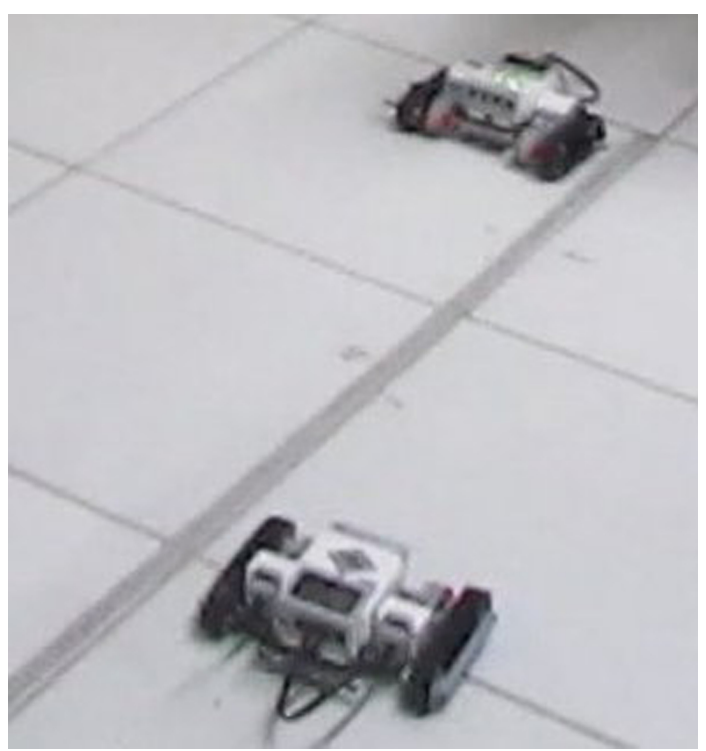

Figura 5: Situação Experimental de Encontro de Corpos em movimentos opostos

simular a situação descrita. Inicialmente tínhamos que garantir que os robôs estivessem em movimento uniforme, ou seja com velocidade constante, desde o início do evento. O robô teria que já estar funcionando quando do posicionamento na reta e quando do seu abandono no instante do disparo do cronômetro. Nossa solução foi que um dos estudantes ficasse responsável pelo acionamento inicial do cronômetro e com a leitura do instante de encontro. Dois outros estudantes ficaram com os carros em funcionamento, cada um deles segurando o robô suspenso sob a posição inicial correspondente $(0 \mathrm{~cm}$ e $100 \mathrm{~cm})$ na pista orientada com a fita métrica e na espera do comando de voz autorizando a colocação dos carros no piso para início do fenômeno, quando do acionamento do cronômetro. Um quarto estudante ficou responsável pelo acompanhamento visual dos carros com reconhecimento do encontro e a leitura da posição final, no momento do encontro das duas extremidades frontais dos robôs. Um quinto estudante ficou com a responsabilidade do comando de 
voz de autorização de destravamento do cronômetro para o início da situação problema, assim como, no instante de detecção do encontro das extremidades dos carros, comandar a leitura final desejada.

Para a finalização da sequência de ensino experimental, propomos uma segunda situação de Encontro de Corpos através de um desafio extra no qual os estudantes deveriam posicionar o carro mais veloz na posição $0 \mathrm{~cm}$ e o outro na posição $30 \mathrm{~cm}$, os deslocamentos ocorrendo no mesmo sentido da trajetória orientada pela fita métrica, para proceder a determinação do instante e da posição de ultrapassagem, através do procedimento experimental associado a determinação matemática, para posterior reflexão e confronto entre estes resultados obtidos.

Diversas vezes estes valores não foram totalmente coincidentes apresentando pequenas discrepâncias ou até em alguns casos uma diferença considerável. Tais discrepâncias, verificadas em diversas sessões, muitas vezes ocorreram por questão das imprecisões impostas pelas leituras experimentais ou por erros cometidos nos procedimentos aplicados quando na resolução da situação problema.

Durante o primeiro desafio, no qual os corpos estavam com sentidos opostos, os estudantes foram solicitados a executar a determinação experimental e teórica dos valores do instante e da posição de encontro dos robôs. Antes do procedimento experimental, na determinação teórica, utilizando as estratégias previamente relatadas, 17 equipes, equivalente a $71 \%$, do total de 24 equipes, conseguiram calcular corretamente o instante e a posição de encontro, enquanto 7 equipes, equivalente a $29 \%$, não conseguiram chegar aos valores corretos.

Das 7 equipes que não obtiveram sucesso, 5 equipes, correspondendo a $21 \%$, erraram no procedimento matemático quando da necessidade de convencionar a velocidade do robô $\mathrm{B}$ com sinal negativo.

Uma das equipes, equivalente a $4 \%$ do total, errou o procedimento matemático, na resolução resultante da Estratégia 1, pois agrupou um termo independente, com um termo com incógnita na solução da equação de $1^{\circ}$ grau. Houve uma equipe que deixou a questão em branco. $\mathrm{E}$ por fim, houve uma equipe que teve a iniciativa de dar suporte e orientar os colegas de como proceder a determinação do instante e a posição de encontro, ação permitida pelo pesquisador, ampliando as inter-relações entre os sujeitos participantes.

O procedimento matemático mais utilizado pelas equipes na resolução do problema de Encontro de Corpos em sentidos opostos foi a Estratégia 1, correspondendo a 21 equipes, o equivalente a $88 \%$ do total de 24 equipes. Este percentual indica a tendência das equipes de adotarem a Estratégia 1 como a mais indicada para a formalização de procedimento aplicado para os diversos contextos.

É importante destacar que as atividades realizadas na vivência experimental foram feitas em equipes, enquanto, que os Testes Diagnóstico e de Avaliação Final foram realizados individualmente. A realização destas atividades ocorreu em sequência temporal, mas com intervalos entre elas, durante os quais houve ação do professor colaborador. O professor colaborador só tomou conhecimento dos resultados dos estudantes nos testes e na vivência experimental, assim como o teor dos instrumentos de coleta, no final da pesquisa. Desta forma, ele não teve a possibilidade de induzir a adoção de uma ou outra estratégia de resolução das questões propostas relativas ao fenômeno de Encontro de Corpos. Apesar disto, as modificações nas estratégias utilizadas pelos alunos, não se devem exclusivamente a etapa de vivência experimental e a utilização da Robótica Educacional, ou ação do professor pesquisador, como poderia parecer num primeiro momento. Mas as ações combinadas desenvolvidas durante a vivência concreta e as articulações dos dois profissionais (professor colaborador e professor pesquisador) durante todo processo, tal como projetado a partir da Engenharia Didática.

Na Análise a Posteriori e na Validação, retomamos a questão da participação do professor colaborador e refletimos que a disponibilização dos resultados parciais, poderia promover uma superação ainda mais significativa dos obstáculos observados.

Ainda nesta etapa também percebemos que durante a concepção da sequência de ensino, nos restringimos a resolver problemas utilizando a situação de apenas tratando os móveis como partículas ou pontos materiais, ou seja, desprezamos a dimensão de comprimento dos móveis diante da dimensão de seus deslocamentos. Aspecto que teve que ser ajustado ainda durante a sequência de ensino experimental, visto que a comparação entre o tempo obtido de forma experimental e o tempo determinado através de procedimentos teórico-matemáticos, no caso de ultrapassagem dos robôs, exigia a conceituação dos robôs como corpo extenso, ou seja, tivemos que considerar o seu comprimento no espaço percorrido pelo robô para dimensionamento do tempo de total ultrapassagem.

\section{Conclusões}

Para sistematizar as conclusões deste trabalho, incialmente resgatamos os nossos objetivos que consistiram no estudo de situações reais do ensino de física, mais especificamente, o Encontro de Corpos de Movimento Uniforme, criadas a partir de atividades de montagem e programação de robótica, a partir do arcabouço teóricometodológico da Engenharia Didática.

Com relação ao conteúdo trabalhado destacamos as dificuldades de superação de obstáculos, visto que alguns deles permaneceram após as vivências experimentais e aplicação dos testes. Há tendência crescente dos estudantes a utilizarem a estratégia de escrever as equações horárias de espaço de cada robô e igualar as suas posições para determinar o instante de encontro através dos problemas propostos. Também sinalizamos a necessidade da abordagem de situações com corpos extensos, assim como situações em que o corpo mais veloz esteja a frente e não ocorra ultrapassagem. 
Os elementos da Engenharia Didática evidenciaram a amplitude de estratégias de resolução dos problemas de Encontro de Corpos que podem ser mobilizadas pelos estudantes, e embora algumas delas sejam incorretas, representam modos de pensar sobre o fenômeno. Neste sentido também conseguimos uma identificação mais sistematizada das dificuldades e obstáculos inerentes à solução dos problemas.

O uso da Robótica Educacional, como elemento concreto, foi determinante na superação de alguns dos obstáculos identificados.

A metodologia da Engenharia Didática, vista a partir da perspectiva de ensino, sinaliza que a superação de obstáculos é complexa e dificilmente pode ser alcançada a partir de intervenções pontuais, mesmo que estas tenham sido cuidadosamente estruturadas. Assim, há necessidade constante de reestruturação das sequencias de ensino, pelos docentes, em função das dificuldades observadas nas realizações das atividades pelos estudantes. Se considerada partir da perspectiva da pesquisa sinaliza a necessidade de maior engajamento entre pesquisador e colaborador (professor da escola). Ou seja, as ações de pesquisa precisam fazer parte da prática do professor e das dinâmicas escolares, de forma que haja uma estreita articulação entre teoria e prática.

A partir dos resultados alcançados no âmbito desta pesquisa, vislumbramos a possibilidade de novas incursões desenvolvendo propostas de ensino estruturadas a partir de elementos da Engenharia Didática utilizando montagens de experimentos com os kits de Robótica Educacional abordando outros conceitos físicos, tais como: Lançamento Horizontal, Lançamento Oblíquo, Choques Mecânicos, Equilíbrio de corpos, Movimento Harmônico Simples entre outros.

Destacamos que a proposta desenvolvida não se constitui num roteiro pronto para ser aplicado, em outros contextos, ou para abordagem de outros conteúdos, mas consiste num planejamento feito a partir de elementos teóricos e metodológicos da Engenharia Didática que possibilita o acompanhamento detalhado da implementação das atividades de ensino.

E desta forma indicamos a Engenharia Didática como um arcabouço para planejamento e monitoramento do ensino de diversos tópicos do currículo de Física salientando que o sucesso do processo de ensino e aprendizagem depende do empenho e cuidado na concepção do desenho e do planejamento da sequência de ensino.

\section{Material Suplementar}

Os seguintes materiais suplementares estão disponíveis online:

Apêndice A - Questionário de Coleta das Experiências de Ensino dos Professores de Física

Apêndice B - Teste Diagnóstico de coleta de dados apresentados no estudo de Encontro de Corpos
Apêndice C - Ficha de Registro da Observação Sequência de ensino: Encontro de Corpos - Carro A

Apêndice D - Relatórios Devolutivos

\section{Referências}

[1] M. Méheut e D. Psillos, International Journal Science Education 26, 515 (2004).

[2] W.A.M. Honorato, Proposta de uma plataforma robótica para o ensino de cinemática. Dissertação de Mestrado, Universidade Federal de Itajubá, Itajubá (2016).

[3] A.P.S. Rabelo, Robótica Educacional no Ensino de Física. Dissertação de Mestrado, Universidade Federal de Goiás, Catalão (2016).

[4] M.R.G. Vazzi, O Arduíno e a Aprendizagem de Física: um kit robótico para abordar conceitos e princípios do Movimento Uniforme. Dissertação de Mestrado, Universidade Estadual Paulista, Araraquara (2017).

[5] S.A. Almouloud e M.J.F. Silva, Rev. Eletr. de Educ. Matemática 7, 39 (2012).

[6] W.M. Pommer, A Engenharia Didática em sala de aula: Elementos básicos e uma ilustração envolvendo as Equações Diofantinas Lineares (Universidade de São Paulo, São Paulo, 2013).

[7] J. Brun, Didáctica das Matemáticas (Instituto Piaget, Porto Alegre, 2000).

[8] R.S. Guimarães, V.E. Barlette e P.H. Guadagnini, Revista Polyphonía 26, 224 (2015).

[9] E.V. Sousa, Objetos de Aprendizagem no Ensino de Matemática e Física: uma proposta interdisciplinar. Dissertação de Mestrado, Pontifícia Universidade Católica, São Paulo (2010).

[10] M.I.S. Berenguer, A aplicação da Engenharia Didática no Ensino das Ciências Exatas. Trabalho de Conclusão de Curso, Universidade Cândido Mendes, Rio de Janeiro (2010).

[11] M. Artigue, in: Didáctica das Matemáticas editado por J. Brun (Horizontes Pedagógicos Instituto Piaget, Lisboa, 1996). 